\title{
Effects of epinephrine and hypotaurine on in-vitro fertilization in the golden hamster
}

\author{
M. Lorraine Leibfried and B. D. Bavister \\ Wisconsin Regional Primate Research Center, 1223 Capitol Court, \\ Madison, Wisconsin 53706, U.S.A.
}

\begin{abstract}
Summary. Using an experimental design in which the addition of hypotaurine or epinephrine was staggered through time, evidence was found that suggests these two compounds are working independently and sequentially to stimulate the fertilizing capacity of hamster spermatozoa in vitro. Prior exposure of spermatozoa to hypotaurine is a prerequisite for the action of epinephrine in causing activation and penetration of hamster ova. A definite role for hypotaurine in inducing capacitation of hamster spermatozoa is also demonstrated.

The $\alpha$-adrenergic antagonist, phentolamine, was more effective in blocking fertilization of hamster ova in vitro than was propranolol, a $\beta$-antagonist. This indicates that catecholamines may be working by way of $\alpha$-adrenergic receptors in causing capacitation of hamster spermatozoa. The failure to block fertilization with phentolamine after epinephrine has exerted its effect implies that epinephrine acts in a hormone-like fashion.
\end{abstract}

\section{Introduction}

For mammalian fertilization to occur spermatozoa must undergo a series of physiological and morphological alterations defined as capacitation and the acrosome reaction. In the golden hamster 3 factors controlling these events in vitro have been identified. A $\beta$-amino acid (taurine or hypotaurine) maintains hamster sperm motility and viability (Mrsny, Waxman \& Meizel, 1979; Meizel, Lui, Working \& Mrsny, 1980) but may also play a role in sperm capacitation (Meizel et al., 1980; Leibfried \& Bavister, 1981). Catecholamines may cause activation of sperm motility (Bavister, Chen \& $\mathrm{Fu}, 1979$ ), a process closely identified with capacitation (Yanagimachi, 1970). They may also cause induction of the acrosome reaction (Cornett \& Meizel, 1978; Meizel \& Working, 1980). Serum albumin allows the occurrence of the acrosome reaction (Lui, Cornett \& Meizel, 1977; Bavister, 1981a) but may also aid capacitation (Meizel, 1978; Bavister, 1981b) and maintain sperm motility and viability (Meizel, 1978).

The presence of a $\beta$-amino acid, a catecholamine and serum albumin in an appropriate physiological saline with energy sources (Bavister \& Yanagimachi, 1977) yields an almost completely defined system for the capacitation and fertilization of hamster gametes in vitro (Leibfried \& Bavister, 1981). Beta-amino acids (Hamner, 1971; Meizel et al., 1980) and serum albumin (Hamner, 1971; Stanke, Sikes, DeYoung \& Tumbleson, 1974) are present in the oviducal fluid of several mammals and oviducal tissue contains catecholamines (Bodkhe \& Harper, 1972). These factors may also be endogenous promoters of fertilization since they are found at the site of fertilization in vivo, the oviduct.

How these 3 agents interact in enabling hamster spermatozoa to penetrate ova is unclear. Analysis of the role of serum albumin in fertilization is not easily amenable to experimental 
manipulation. Although a synthetic macromolecule, polyvinyl alcohol, can replace albumin in maintaining sperm viability and motility, serum albumin is still essential for the occurrence of acrosome reactions in vitro (Bavister, 1981b). The $\beta$-amino acids and catecholamines together stimulate the fertilizing ability of spermatozoa in the presence of serum albumin (Leibfried \& Bavister, 1981), but individually are less effective in maintaining motility (Bavister et al., 1979; Leibfried \& Bavister, 1981), or causing activation and acrosome reactions (Cornett \& Meizel, 1978; Mrsny et al., 1979; Meizel et al., 1980) and fertilization (Cornett, Bavister \& Meizel, 1979; Leibfried \& Bavister, 1981). The purpose of the present study was to examine further the interactions between hypotaurine and epinephrine in stimulating the fertilizing ability of hamster spermatozoa.

\section{Materials and Methods}

\section{General}

The methods used for obtaining fertilization in vitro were as previously described (Leibfried $\&$ Bavister, 1981). The only departure from these techniques was the use of (-)-epinephrine for the catecholamine. A stock solution containing (-)-epinephrine $(25 \mu \mathrm{M})$, hypotaurine $(250 \mu \mathrm{M})$, D-penicillamine $(500 \mu \mathrm{M})$, sodium metabisulphite $(500 \mu \mathrm{M})$ and sodium lactate $(3 \mathrm{mM})$ dissolved in saline $(9.21 \mathrm{~g} \mathrm{NaCl} / 1$ of $\times 3$ distilled water) was prepared, divided into aliquants and frozen until just before use. When epinephrine or hypotaurine were to be administered separately, (-)-epinephrine stock solutions were made as described above with the elimination of hypotaurine. Stock solutions of hypotaurine $(250 \mu \mathrm{M})$ were prepared in saline alone, divided into portions and frozen until required. Stocks of the catecholamine antagonists $(250 \mu \mathrm{M})$, phentolamine and propranolol, dissolved in saline, were made shortly before use. All reagents mentioned in this paragraph and succeeding portions of 'Materials and Methods' were obtained from Sigma Chemical Co., St Louis, Missouri, except for phentolamine (CIBA Pharmaceutical Co., Summit, New Jersey).

Droplets of culture medium under paraffin oil in Petri dishes (Falcon Plastics, \#1007) were used for sperm and egg incubations. The final volume of all droplets was $50 \mu \mathrm{l}$. To droplets of the appropriate size were added $2 \mu \mathrm{l}$ of the hypotaurine and/or (-)-epinephrine stocks for final concentrations of 10 and $1 \mu \mathrm{M}$, respectively, and 1 to $4 \mu \mathrm{l}$ of the antagonists to yield concentrations of $5,10,15$ or $20 \mu \mathrm{M}$. Whenever the volume of additions varied between treatments in an experiment, droplets with fewer additions were supplemented with appropriate volumes of saline.

Hamster spermatozoa were recovered from each cauda epididymidis of adult males and inseminated into droplets at concentrations of approximately $1-4 \times 10^{5}$ spermatozoa $/ \mathrm{ml}$ (Leibfried \& Bavister, 1981). Ova were recovered from female golden hamsters that had received 25 i.u. PMSG on the day of the post-oestrous discharge followed $48-54 \mathrm{~h}$ later by 25 i.u. hCG. Ova surrounded by the cumulus oophorus were removed from oviducts $15-17 \mathrm{~h}$ after the hCG and placed into medium containing $1 \mathrm{mg}$ hyaluronidase $/ 3 \mathrm{ml}$ and $0.01 \mathrm{mg}$ soybean trypsin inhibitor $/ \mathrm{ml}$. After cumulus removal was complete (a period of 10-15 min), ova were recovered, pooled from all animals, rinsed 3 times in medium and added to treatment droplets containing spermatozoa. The medium used for recovery and rinsing of ova was similar to the modified Tyrode's used for culture except that the concentration of $\mathrm{NaHCO}_{3}$ was reduced to $2 \mathrm{mM}$ and Hepes buffer $(10 \mathrm{mM})$ was added. The $\mathrm{pH}$ of this medium was 7.4 in air at $20-25^{\circ} \mathrm{C}$.

After sperm/ova cultures had incubated for $1 \frac{1}{2}-2 \mathrm{~h}, 25 \mu \mathrm{l} 10 \%$ neutral buffered formalin were added to the droplets to halt further development. Ova were removed from the culture and agitated in a pipette to dislodge excess spermatozoa. They were then transferred to microscope slides and compressed slightly with coverslips ringed with petroleum jelly for microscopic examination. Ova were classified as having: (a) spermatozoa in the perivitelline space; (b) 
decondensing sperm heads in the vitellus; and (c) male pronucleus, female pronucleus, two polar bodies and a sperm tail in the vitellus. Proportions of ova found in the 3 stages of fertilization never differed between treatments within an experiment or between experiments. For the purpose of this paper ova were scored as penetrated if observed in any of the 3 stages of fertilization. The majority of penetrated ova had decondensing or pronuclear spermatozoa in the vitellus (see footnotes, Tables 2, 3 and 4).

\section{Experimental designs}

Experiments 1 and 2. Experiment 1 was designed to determine the time course of effects exerted by epinephrine and hypotaurine and whether they have sequential or synergistic effects. Seven treatment groups were utilized. One contained both epinephrine and hypotaurine throughout the incubation period, 3 groups contained hypotaurine throughout and 3 groups contained epinephrine throughout the period of culture. At 2 and $4 \mathrm{~h}$ after the start of sperm incubation, epinephrine or hypotaurine was added to groups lacking these compounds at the start of sperm incubation. Two groups received only epinephrine or hypotaurine during the period of culture. At 2, 4 and $6 \mathrm{~h}$ of incubation, the percentage of motile spermatozoa was estimated. Activation (spermatozoa demonstrating the whiplash movement characteristic of capacitated hamster spermatozoa) was scored as 0 (no spermatozoa), 1 ( $<50 \%$ motile spermatozoa activated) or 2 (most motile spermatozoa activated). Triplicate observations were made for each treatment within a replicate. Replication was over days using a new male each time $(r=6)$.

The design of Exp. 2 was similar to that of Exp. 1 except that the percentage of ova fertilized in vitro by spermatozoa was the endpoint observed. Ova were added to incubations of spermatozoa $6 \mathrm{~h}$ after the beginning of culture and removed $1 \frac{1}{2}-2 \mathrm{~h}$ after exposure to spermatozoa. Again replication was over days $(r=6)$.

Experiment 3. The dose-response of spermatozoa to phentolamine and propranolol was examined. Four concentrations $(5,10,15$ and $20 \mu \mathrm{M})$ were tested for both antagonists. Ova were added to incubations of spermatozoa $4 \mathrm{~h}$ after the beginning of culture and examined for stage of fertilization $1 \frac{1}{2}-2 \mathrm{~h}$ later. All treatments contained epinephrine and hypotaurine. The endpoint used for statistical analysis was the percentage of ova penetrated. Replication was done over days $(r=6)$.

Experiment 4. This experiment was designed to determine when epinephrine becomes necessary in causing sperm activation and capacitation and if it icting as a hormone-like stimulus. Epinephrine and hypotaurine were present in all treatments. Phentolamine (15 $\mu \mathrm{M})$ was added to different groups at $0,1,2,3$ and $4 \mathrm{~h}$ of sperm incubation. Ova were placed with spermatozoa after $5 \mathrm{~h}$ of culture and removed $1 \frac{1}{2} 2 \mathrm{~h}$ later and examined for penetration. Replication was over days $(r=7)$.

\section{Statistical analysis}

An analysis of variance for 1-way classifications was used to analyse all experimental data. In Exp. 1, individual analyses were performed for each of the 3 observation times. Treatments with no variation were not included in the analyses. When treatment effects were significant, Duncan's multiple range test was used to determine which treatment means were different. Both the 1-way ANOVAs and Duncan's tests were done using the SAS computing programme (Barr, Goodnight, Sall \& Helwig, 1976).

\section{Results}

\section{Experiments 1 and 2}

Hypotaurine and epinephrine had sequential effects on capacitation of hamster spermatozoa. When only epinephrine was present at the beginning of sperm incubation, motility decreased to 
Table 1. Effect of adding hypotaurine and epinephrine after the beginning of incubation on motility and activation of hamster spermatozoa

\begin{tabular}{|c|c|c|c|c|c|}
\hline \multirow[b]{3}{*}{ Treatment* } & \multicolumn{5}{|c|}{ Time of observation } \\
\hline & \multirow{2}{*}{$\frac{2 \text { hours }}{\% \text { Motility } \dagger}$} & \multicolumn{2}{|c|}{4 hours } & \multicolumn{2}{|c|}{6 hours } \\
\hline & & $\%$ Motility ${ }^{\dagger}$ & Activation $\ddagger$ & $\%$ Motility $\dagger$ & Activation $\ddagger$ \\
\hline $\mathrm{Ht}+\mathrm{Epi}$ & a85.2 \pm 2.5 & $\mathrm{a} 64 \cdot 0 \pm 3 \cdot 0$ & ${ }^{\mathrm{a}} 1.08 \pm 0.08$ & ${ }^{\mathrm{a}} 50.5 \pm 4.7$ & ${ }^{\mathrm{a}} 1.34 \pm 0.22$ \\
\hline $\mathrm{Ht}+$ Epi at $2 \mathrm{~h}$ & b $71.8 \pm 4.3$ & $65.0 \pm 4.4$ & ${ }^{\mathrm{a}} 1.29 \pm 0.17$ & $\mathrm{a}, \mathrm{b} 43 \cdot 3 \pm 5 \cdot 4$ & ${ }^{\mathrm{a}} 1 \cdot 19 \pm 0.13$ \\
\hline $\mathrm{Ht}+$ Epi at $4 \mathrm{~h}$ & $\mathrm{~b} 69.3 \pm 5.2$ & $b_{43.0 \pm 10.0}$ & ${ }^{b} 0.29 \pm 0.19$ & ${ }^{b} 35.2 \pm 8.0$ & ${ }^{\mathrm{a}} 0.93 \pm 0.16$ \\
\hline Ht only & $b 88.0 \pm 5.7$ & b $36.8 \pm 11 \cdot 1$ & ${ }^{b} 0.33 \pm 0.12$ & ${ }^{c} 11.2 \pm 3.4$ & $b_{0} 0.04 \pm 0.04$ \\
\hline $\mathrm{Epi}+\mathrm{Ht}$ at $2 \mathrm{~h}$ & $c_{4} \cdot 0 \pm 2 \cdot 0$ & ${ }^{c} 11 \cdot 3 \pm 3.7$ & ${ }^{b} 0.13 \pm 0.13$ & ${ }^{c} 6.5 \pm 1.2$ & ${ }^{b} 0.13 \pm 0.13$ \\
\hline $\mathrm{Epi}+\mathrm{Ht}$ at $4 \mathrm{~h}$ & $3.8 \pm 2.2$ & 0 & - & 0 & - \\
\hline Epi only & ${ }^{c} 4 \cdot 0 \pm 2 \cdot 0$ & 0 & - & 0 & - \\
\hline
\end{tabular}

All means $( \pm$ s.e.m.) are based on 6 replicates, each replicate containing triplicate observations per treatment.

* $\mathrm{Ht}=$ hypotaurine $(10 \mu \mathrm{M})$. Epi $=(-)$-epinephrine $(1 \mu \mathrm{M})$. These agents were present throughout the period of sperm incubation unless stated otherwise.

† Mean percentage of motile spermatozoa present at the time of observation. Treatment means with different superscripts are different $(P<0.05)$ within each time.

$\ddagger$ Subjective estimate of the number of spermatozoa demonstrating the whiplash flagellar movement of capacitated hamster spermatozoa (see text). Treatment means with different superscripts are different $(P<0.05)$ within each time.

low levels after $2 \mathrm{~h}$ and could not be restored by adding hypotaurine at 2 or $4 \mathrm{~h}$ of culture (Table 1). When hypotaurine was added after $2 \mathrm{~h}$ of culture, activation was sometimes seen in the small percentage of spermatozoa that remained motile (Table 1) but penetration of ova did not occur (Table 2). Hypotaurine did not merely maintain sperm motility and viability. After 2 or $4 \mathrm{~h}$ of incubation, if epinephrine was added to sperm cultures containing hypotaurine, by the next $2 \mathrm{~h}$ observation period activation was observed and was comparable to treatments receiving epinephrine $2 \mathrm{~h}$ earlier (Table 1). This is shorter than the normal 3-4 $\mathrm{h}$ needed for the capacitation of hamster spermatozoa in vitro (Yanagimachi, 1969). The ability of hamster spermatozoa to penetrate ova was equal when epinephrine was added to sperm cultures containing hypotaurine at 0,2 or $4 \mathrm{~h}$ of incubation (Table 2). Although not presented as separate data, the stage of fertilization reached during the time allotted for sperm/ova incubation did not

Table 2. Effect of adding hypotaurine or epinephrine after the start of sperm incubation on fertilization in vitro

\begin{tabular}{lcc}
\hline Treatment* & Total no. of ova & $\begin{array}{c}\text { Means } \pm \text { s.e.m. } \\
\text { penetration }(\%) \ddagger\end{array}$ \\
\hline $\mathrm{Ht}+$ Epi & 165 & ${ }^{\mathrm{a}} 71.7 \pm 9.8$ \\
$\mathrm{Ht}+$ Epi at $2 \mathrm{~h}$ & 153 & ${ }^{\mathrm{a}} 69.9 \pm 9.0$ \\
$\mathrm{Ht}+$ Epi at $4 \mathrm{~h}$ & 150 & ${ }^{\mathrm{a}} 52.8 \pm 12.3$ \\
$\mathrm{Ht}$ only & 168 & ${ }^{\mathrm{b}} 6.6 \pm 4.6$ \\
Epi + Ht at $2 \mathrm{~h}$ & 156 & 0
\end{tabular}

${ }^{*} \mathrm{Ht}=$ hypotaurine $(10 \mu \mathrm{M})$. Epi $=(-)$-epinephrine $(1 \mu \mathrm{M})$ Agents were present throughout the period of sperm incubation unless stated otherwise.

† Incubated with spermatozoa over 6 replicates. Ova added $6 \mathrm{~h}$ after the start of sperm incubation.

$\ddagger$ An ovum was considered penetrated if spermatozoa were found in the perivitelline space or at any subsequent stage of fertilization. Vitelline spermatozoa were found in $75 \%$ of penetrated ova. Treatment means with different superscripts are different $(P<0.05)$ 
Table 3. Effect of dose of phentolamine or propranolol on hamster fertilization in vitro

\begin{tabular}{lccc}
\hline $\begin{array}{c}\text { Catecholamine } \\
\text { antagonist }\end{array}$ & $\begin{array}{c}\text { Dose } \\
(\mu \mathrm{M})\end{array}$ & $\begin{array}{c}\text { Total no. } \\
\text { of ova* }\end{array}$ & $\begin{array}{c}\text { Mean } \pm \text { s.e.m. } \\
\text { penetration }(\%) \dagger\end{array}$ \\
\hline None & - & 101 & a $93.2 \pm 2.8$ \\
Propranolol & 5 & 103 & a $84.4 \pm 10 \cdot 6$ \\
& 10 & 105 & a $83.5 \pm 6 \cdot 1$ \\
& 15 & 106 & a.b $70.8 \pm 8 \cdot 3$ \\
Phentolamine & 20 & 99 & b $57 \cdot 1 \pm 14.5$ \\
& 5 & 107 & b.c $50.3 \pm 14.0$ \\
& 10 & 103 & c.d $31 \cdot 8 \pm 15.4$ \\
& 15 & 103 & d $13.0 \pm 13.0$ \\
& 20 & 103 & 0 \\
\hline
\end{tabular}

* Incubated with spermatozoa over 6 replicates. Ova added $4 \mathrm{~h}$ after the start of sperm incubation.

† An ovum was considered penetrated if spermatozoa were found in the perivitelline space or at any subsequent stage of fertilization. Vitelline spermatozoa were found in $86 \%$, of penetrated ova. Treatment means with different superscripts are different $(P<0.05)$.

differ between treatments in this experiment or subsequent experiments. This implies that penetration of ova by spermatozoa began at essentially the same time across treatments.

\section{Experiment 3}

At all 4 concentrations phentolamine was more effective in blocking penetration of ova by hamster spermatozoa than was propranolol (Table 3). At $5 \mu \mathrm{M}$, phentolamine impaired the fertilizing ability of spermatozoa whereas propranolol had no effect until a concentration of $20 \mu \mathrm{M}$ was reached. Phentolamine or propranolol at a concentration of $20 \mu \mathrm{M}$ decreased the percentage of motile spermatozoa present by 3-4 h of incubation. A dose of $15 \mu \mathrm{M}$ phentolamine was chosen for the next experiment since it effectively blocked fertilization (Table 3) without impairing sperm motility.

\section{Experiment 4}

Phentolamine was most effective in preventing fertilization in vitro when added within the first $3 \mathrm{~h}$ of sperm incubation (Table 4). Addition at later times ( 3 or $4 \mathrm{~h}$ of incubation) gave progressively less impairment of fertilization.

\section{Discussion}

Sequential roles for hypotaurine and epinephrine in stimulating the fertilizing ability of hamster spermatozoa were demonstrated in Exps 1 and 2. Prior exposure of spermatozoa to hypotaurine was a prerequisite for the action of epinephrine in causing activation of spermatozoa and penetration of ova. A definite role for hypotaurine in stimulating capacitation of spermatozoa was also demonstrated. If the addition of epinephrine to cultures of sperm containing hypotaurine was delayed for 2 or $4 \mathrm{~h}$, activation was observed after incubation for a further $2 \mathrm{~h}$. This is a shorter interval than the normal 3-4 h of incubation needed for activation of hamster spermatozoa in vitro (Yanagimachi, 1969). 
Table 4. Effect of adding phentolamine at intervals after the start of sperm incubation on hamster fertilization in vitro

\begin{tabular}{ccc}
\hline $\begin{array}{c}\text { Time of addition* } \\
(\mathrm{h})\end{array}$ & Total no. of ova ${ }^{*}$ & $\begin{array}{c}\text { Mean } \pm \text { s.e.m. } \\
\text { penetration (\%) } \ddagger\end{array}$ \\
\hline No additions & 179 & ${ }^{\mathrm{a}} 77 \cdot 2 \pm 4 \cdot 6$ \\
0 & 162 & ${ }^{\mathrm{c}} 7.2 \pm 6 \cdot 3$ \\
1 & 163 & ${ }^{\mathrm{c}} 14 \cdot 2 \pm 11.9$ \\
2 & 176 & ${ }^{\mathrm{c}} 23.0 \pm 13 \cdot 0$ \\
3 & 177 & ${ }^{\mathrm{b}} 45 \cdot 5 \pm 10 \cdot 0$ \\
4 & 173 & ${ }^{\mathrm{a}} 65 \cdot 5 \pm 12.0$ \\
\hline
\end{tabular}

* Time from beginning of incubation at which phentolamine $(15 \mu \mathrm{M})$ was added.

$\dagger$ Incubated with spermatozoa over 7 replicates. Ova were added $5 \mathrm{~h}$ after the start of sperm incubation.

$\ddagger$ An ovum was considered penetrated if spermatozoa were found in the perivitelline space or at any subsequent stage of fertilization. Vitelline spermatozoa were found in $80 \%$ of penetrated ova. Treatment means with different superscripts are different $(P<0.05)$.

In the presence of hypotaurine only, no significant level of activated motility was found, a result that is similar to previous work from our laboratory (Leibfried \& Bavister, 1981) and that is compatible with earlier work using adrenal extracts of the sperm motility factor (Bavister $e t$ al., 1979), now known to be one of the $\beta$-amino acids. Cornett \& Meizel (1978) also found that adrenal extracts of sperm motility factor were ineffective in inducing activation of hamster spermatozoa unless catecholamines were present. Later work from the same laboratory, and using hypotaurine rather than adrenal extracts as source of sperm motility factor, showed high levels of activated motility even without catecholamines (Meizel et al., 1980). There are major differences in incubation methods between the work reported here and the results obtained by Meizel et al. (1980) including their use of 10-fold higher sperm concentration, 50-fold increase in hypotaurine and 3-fold greater bovine serum albumin. The most striking difference between the work of Meizel et al. (1980) and the results reported here is the use of a selected suspension of hamster spermatozoa produced by elution through a glass bead column (Lui, Mrsny \& Meizel, 1979). Earlier work (Cornett \& Meizel, 1978) in which non-selected sperm populations were used yielded results that are compatible with ours. Whether or not the use of a pre-selected population of spermatozoa accounts for the disparity, the work reported here provides no evidence for suggesting that hypotaurine alone is capable of inducing significant activation of motility or fertility in hamster spermatozoa.

The effects of hypotaurine on hamster spermatozoa in vitro, leading to capacitation, occur within the first $2 \mathrm{~h}$ of sperm incubation. This was indicated by the motility and activation (Table 1) and fertility (Table 2) of spermatozoa when epinephrine was added at $2 \mathrm{~h}$ versus $0 \mathrm{~h}$ incubation and the inability to block fertilization completely with phentolamine when added after $2 \mathrm{~h}$ of culture (Table 4). After sensitization of spermatozoa by hypotaurine, addition of epinephrine may be delayed until at least $4 \mathrm{~h}$ after the start of incubation and still cause significant levels of activation (Table 1) and fertility (Table 2). Epinephrine, therefore, can be the direct stimulus for activation and possibly the acrosome reaction since its effect is more closely linked in time to these events compared to hypotaurine.

Failure to block fertilization in vitro by the addition of a catecholamine antagonist after $2 \mathrm{~h}$ of sperm incubation suggests that epinephrine acts by way of a hormone-like stimulus. Identification of adrenergic receptors on spermatozoa would provide definitive evidence for this. Phentolamine, an $\alpha$-adrenergic antagonist was more effective in blocking fertilization than was propranolol, a $\beta$-adrenergic antagonist, yet both $\alpha$ - and $\beta$-agonists have been shown to stimulate 
motility, activation and acrosome reactions in hamster spermatozoa (Cornett \& Meizel, 1978; Bavister et al., 1979; Meizel \& Working, 1980). If epinephrine is truly interacting with adrenergic receptors on spermatozoa, it is not clear whether $\alpha$ - or $\beta$-receptors or both are involved.

In summary, evidence is presented that suggests hypotaurine and epinephrine are working independently and sequentially to stimulate the fertilizing capacity of hamster spermatozoa. The cellular mechanisms being affected by these agents must now be elucidated.

We thank Dr Michael E. Davis for help in analysing the data. This work was supported by Grant No. HD14235 from the National Institute of Health (B.D.B.) and by the Wisconsin Regional Primate Research Center. This is publication No. 21-025 of the WRPRC.

\section{References}

Barr, A.J., Goodnight, J.H., Sall, J.P. \& Helwig, J.T. (1976) A guide to SAS 76. SAS Institute, P.O. Box 10066, Raleigh, North Carolina.

Bavister, B.D. (1981a) Substitution of a synthetic polymer for protein in a mammalian gamete culture system. J. exp. Zool. 217, 45-51.

Bavister, B.D. (1981b) Bovine serum albumin is required for efficient capacitation of hamster sperm in vitro. Biol. Reprod., Suppl. 1, 24, Abstract 37.

Bavister, B.D. \& Yanagimachi, R. (1977) The effects of sperm extracts and energy sources on the motility and acrosome reaction of hamster sperm in vitro. Biol. Reprod. 161, 228-237.

Bavister, B.D., Chen, A.F. \& Fu, P.C. (1979) Catecholamine requirement for hamster sperm motility in vitro. J. Reprod. Fert. 56, 507-513.

Bodkhe, R.R. \& Harper, M.J.K. (1972) Changes in the amount of adrenergic neurotransmitter in the genital tract of untreated rabbits and rabbits given reserpine or iproniozid during the time of egg transport. Biol. Reprod. 6, 288-299.

Cornett, L.E. \& Meizel, S. (1978) Stimulation of in vitro activation and the acrosome reaction of hamster sperm by catecholamines. Proc. natn. Acad. Sci. U.S.A. 75, 4954-4958.

Cornett, L.E., Bavister, B.D. \& Meizel, S. (1979) Adrenergic stimulation of fertilizing ability in hamster spermatozoa. Biol. Reprod. 20,925-927.

Hamner, C.E. (1971) Composition of oviductal and uterine fluids. $A d v$. Biosci. 6, 143-164.

Leibfried, M.L. \& Bavister, B.D. (1981) The effects of taurine and hypotaurine on in vitro fertilization in the golden hamster. Gamete Res. 4, 57-63.

Lui, C.W., Cornett, L.E. \& Meizel, S. (1977) Iden- tification of the bovine follicular fluid protein involved in the in vitro induction of the hamster sperm acrosome reaction. Biol. Reprod. 17, 24-41.

Lui, C.W., Mrsny, R.J. \& Meizel, S. (1979) Procedures for obtaining high percentages of viable in vitro capacitated hamster sperm. Gamete Res. 2, 207-211.

Meizel, S. (1978) The mammalian sperm acrosome reaction, a biochemical approach. In Development in Mammals, Vol. 3, pp. 1-64. Ed. M. H. Johnson. Elsevier, North Holland Press, Amsterdam.

Meizel, S. \& Working, P.K. (1980) Further evidence suggesting the hormonal stimulation of hamster sperm acrosome reactions by catecholamines in vitro. Biol. Reprod. 22, 211-216.

Meizel, S., Lui, C.W., Working, P.K. \& Mrsny, R.J. (1980) Taurine and hypotaurine: their effects on motility, capacitation and the acrosome reaction of hamster sperm in vitro and their presence in sperm and reproductive tract fluids of several mammals. Develop. Growth Different. 22, 483-494.

Mrsny, R.J., Waxman, L. \& Meizel, S. (1979) Taurine maintains and stimulates motility of hamster sperm during capacitation in vitro. J. exp. Zool. 210 , 123-128.

Stanke, D.F., Sikes, J.D., DeYoung, D.W. \& Tumbleson, M.E. (1974) Proteins and amino acids in bovine oviductal fluids. J. Reprod. Fert. 38, 493-496.

Yanagimachi, R. (1969) In vitro capacitation of hamster spermatozoa by follicular fluid. J. Reprod. Fert. 18, 275-286.

Yanagimachi, R. (1970) The movement of golden hamster spermatozoa before and after capacitation. J. Reprod. Fert. 23, 193-196.

Received 22 October 1981 